\title{
Şanlıurfa koşullarında ekinezyanın (Echinacea purpurea (L.) Moench) verim ve bazı bitkisel özeliklerinin belirlenmesi
}

\section{Determination of yield and some plant properties of Echinacea purpurea (L.) Moench under the Şanlıurfa conditions}

\author{
Mine SATICI ${ }^{1}$ iD , Abdulhabip ÖZEL ${ }^{2 *}$ iD \\ ${ }^{1}$ Harran Üniversitesi Fen Bilimleri Enstitüsü, Tarla Bitkileri Anabilim Dalı, 63040, Şanlıurfa \\ 2 Harran Üniversitesi Ziraat Fakültesi Tarla Bitkileri Bölümü, 63040, Şanlıurfa
}

To cite this article:

Satıcı, M. \& Özel, A. (2021). Şanlıurfa koşullarında ekinezyanın (Echinacea purpurea (L.) Moench) verim ve bazı bitkisel özeliklerinin belirlenmesi. Harran Tarım ve Gıda Bilimleri Dergisi, 25(1): 4152.

DOI:10.29050/harranziraat.758313

Address for Correspondence: Abdulhabip ÖZEL e-mail:

hozel@harran.edu.tr

Received Date: 26.06.2020 Accepted Date: 17.11.2020

(C) Copyright 2018 by Harran University Faculty of Agriculture. Available on-line at www.dergipark.gov.tr/harranziraat

\section{öz}

Araştırma, Ekinezyanın (E. purpurea (L.) Moench) verim ve bazı tarımsal özelliklerini belirlemek amacıyla, Şanlıurfa koşullarında yürütülmüştür. Gözlemler 2017 yılında dikilen bitkilerde, 2018 yaz süresince tesadüfen seçilen, 50 bitkide alınmıştır. Sezon boyunca, bitkilere göre 1-4 biçim alınmış ve biçimlere göre bitki boyu $(5.00-70.00 \mathrm{~cm})$, sap sayısı $\left(1.00-5.00\right.$ adet ocak $\left.^{-1}\right)$, yan dal sayısı (0.00-16.00 adet bitki $\left.{ }^{-1}\right)$, çiçek sayısı (1.00-17.00 adet bitki $\left.{ }^{-1}\right)$, taze herba verimi (1.00$\left.270.70 \mathrm{~g} \mathrm{bitki}^{-1}\right)$, kuru herba verimi $\left(0.078-69.76 \mathrm{~g} \mathrm{bitki}^{-1}\right)$, kuru yaprak verimi $(0.005-22.54 \mathrm{~g}$ bitki $\left.{ }^{-1}\right)$, taze çiçek verimi (1.00-76.58 $\left.\mathrm{g} \mathrm{bitki}^{-1}\right)$, kuru çiçek verimi $\left(0.014-17.79 \mathrm{~g} \mathrm{bitki}^{-1}\right)$, taze kök verimi (4.78-94.85 $\mathrm{g} \mathrm{bitki}^{-1}$ ) ve kuru kök verimi (1.35-35.73 $\mathrm{g} \mathrm{bitki}^{-1}$ ) gözlemleri alınmıştır. Ayrıca, kuru yaprakta uçucu yağ oranı, kuru kökte uçucu yağ oranı, kuru sapta uçucu yağ oranı, kuru çiçekte uçucu yağ oranı ve kuru rozet yaprakta uçucu yağ oranı ve bitki organlarına göre uçucu yağ bileşenleri dağılımı belirlenmiştir. İncelenen özellikler yönünden bitkiler arasında büyük varyasyonlar saptanmış ve en yüksek değerler birinci biçimden elde edilmiştir. Genel olarak sıcaklık artışı geciken biçimlerde verimi düşürmüştür.

Anahtar Kelimeler: Echinacea purpurea, Bitkisel özellikler, Uçucu yağ oranı, Uçucu yağ bileşenleri

\section{ABSTRACT}

The research was carried out to determine the yield and some agricultural characteristics of Echinacea (Echinacea purpurea (L.) Moench) in Şanlıurfa conditions. All observations were taken on 50 plants, selected by randomized, during the summer of 2018 in plants planted in 2017. Throughout the season, 1-4 harvests were taken according to the plants. During the research, plant heights $(5.00-70.00 \mathrm{~cm})$, numbers of stem $\left(1.00-5.00\right.$ number plant $\left.{ }^{-1}\right)$, branches numbers (0.00-16.00 number stem $\left.{ }^{-1}\right)$, flower numbers (1.00-17.00 number plant $\left.{ }^{-1}\right)$, fresh herb yields (1.00-270.70 g plant $\left.^{-1}\right)$, dry herb yields (0.078-69.76 g plant $\left.^{-1}\right)$, dry leaf yields (0.005-22.54 g plant $\left.^{-1}\right)$, fresh flower yields (1.00-76.58 g plant $\left.^{-1}\right)$, dry flower yields (0.014-17.79 $\left.\mathrm{g} \mathrm{plant}^{-1}\right)$ and fresh root yields (1.35-35.73 g plant $^{-1}$ ) observations were made at each harvest. Also besides, essential oil ratio in the dry leaf, dry root, dry stem, dry flower, and dry rosette, and distribution of essential oil components by plant organs were determined. In terms of the characteristics studied, large variations were detected among the plants, and the highest values were obtained from the first harvest. Overall, it was reduced yields in delayed harvests due to an increase in temperature.

Key Words: Echinacea purpurea, Plant characteristics, Volatile oil rate, components of essential oil 


\section{Giriş}

Ekinezya, Kuzey Amerika kökenli, Asteraceae familyasından çok yıllık otsu bitkidir (Mat, 2002). Amerika ve Kanada da bulunan Ekinezya türleri Kuzey Amerika'nın endemik bitkilerinden biri olarak tanınmaktadır. Ülkemizde bu bitki ekinezya, erguvani kirpibaşı, kirpi otu, ince yapraklı eflatun koza çiçeği, samson kökü olarak adlandırılır (Küçükali, 2012)

Ekinezya çok yönlü bir kullanım alanına sahiptir. Ekinezyanın sığır ve atların yemlerine ilave katkı olarak verildiğinde, iştah $\mathrm{acıc}$ ve büyümeye etkili olduğu bildirilmiştir (Kindscher, 1989). Amerika Birleşik Devletleri'nde genellikle diyet için kullanılan ekinezya bitkisi; Almanya'da ise, çoğu Ekinezya ürünü ilaç olarak lisanslanmış ve eczanelerde satılır durumdadır (Mat, 2002). Ekinezya bitkisinden elde edilen ilaçlar; enfeksiyonları gidermede ve bağışıklık sistemini güçlendirmek için kullanılmaktadır. Ekinezya türleri, Amerika yerlileri tarafından yaraların tedavisinde, baş ağrılarına ve mide ağrılarına bağlı hastalıklarda ve bronşit gibi kronik hastalıklarda kullanılmıştır. Farmakolojik etkileri tam olarak ispatlanmamış olmakla birlikte yapılan çalışmalar bağışıklık sisteminin uyarıcı olarak bilinmektedir (Omidbaigi, 2002). Ekinezya bitkisinin kökünden hazırlanan preparatlar, üst solunum yolu ve idrar yolu enfeksiyonlarının tedavisinde kullanılır. Bugün, ekinezya türlerinden elde edilen preparatlar, özellikle Avrupa ülkeleri ve ABD başta olmak üzere, dünya bitkisel ilaç pazarında önemli bir yere sahiptir (Mat, 2002). En yaygın kullanım alanları bitkisel çaydır, ayrıca antioksidan etkilere sahiptir (Gülpınar, 2009). Bu nedenlerle Echinacea üretimi, tarımsal alanlarda, yaygınlaşmaktadır.

Echinacea'nın tedavide etkisi olan, kafeik asit ve türevleri (kikorik asit, ekinakosit ve klorogenik asit gibi), lipofilik asit ve türevleri (izobutilamit oluşturan alkalamitler) ve uçucu yağlarıdır. Kafeik asit ve türevlerinin genel olarak, antibakteriyel ve antiviral etkiye sahip olduğunu bildirilmektedir (Bauer, 1998; Adam, 2002; Omidbaigi, 2002). Kuzey Amerika'ya özgü çok yıllık bir bitki olan ekinezya günümüzde pek çok ülke tarafından yetiştirilmekte ticareti yapılmaktadır (Parmenter ve ark., 1992; Bruneton, 1999; Schar, 1999). Ülkemiz için yeni bir bitki olan ekinezyanın adaptasyonu ve yetiştirilme tekniğinin belirlenmesi ile ilgili çalışmalar, bazı bölgelerde, yapılmış (Çoksarı, 2012; Küçükali, 2012; Şahan, 2012; Yeşil ve Kan, 2013; Özcan, 2014; Çelik, 2016; Ulutaş, 2016) ancak, Şanlıurfa koşullarında hiç çalışılmamıştır.

Yapılan bazı çalışmalarda ekinezyanın ekolojik koşullara, genotipe (Mat, 2002; Yeşil ve Kan, 2013) ve yetiştirme tekniğine (Parmenter ve Littlejohn, 1997; Muntean ve ark., 1998; Dufault ve ark., 2003; Kreft, 2005; Chen ve ark., 2008; Çoksarı, 2012; Küçükali, 2012; Özcan, 2014; Soldamlı, 2016; Ulutaş, 2016) göre verim ve kalitesinin değiştiği bildirilmiştir.

Türkiye'de üretimi sınırlı yapılan ekiznezya bitkisinin, uygun bölgelerde tarımının yapılması; küçük üreticiler için yeni ve alternatif bir geçim kaynağı olması, ekinezya bitkisini işleyecek sektörlerin kurulmasına ve gelişmesine katkı sağlayacak olması ve ihracat potansiyelinin yüksekliği nedenleriyle önemli bir bitkidir. Bölgemiz koşullarında ilk defa yapılan bu çalışma ile ekinezyanın Şanlıurfa koşullarında, verim potansiyeli ve bazı bitkisel özellikleri belirlenmiştir. Bu sonuçlar, daha sonra yapılacak çalışmalara zemin oluşturması bakımından önemli olabilir.

Bu çalışma, Şanlıurfa koşullarında Ekinezyanın (E. purpurea) verim, bazı bitkisel özellikler ve uçucu yağ bileşenlerini belirlemek amacıyla, yürütülmüştür.

\section{Materyal ve Yöntem}

\section{Materyal}

Araştırmalarda, Echinacea cinsine ait olan Echinacea purpurea (L.) Moench türü materyal olarak kullanılmıştır. Bitki tohumları, Ege Tarımsal Araştırma Enstütisinden temin edilmiştir.

Araştırma, Harran Üniversitesi Osmanbey yerleşkesinde, Ziraat Fakültesi Tarımsal Araştırmalar ve Uygulama Alanının'da, 2018 yılında yürütülmüştür. Şanlıurfa ili, araştırma yılı ve uzun yıllar iklim verileri Çizelge 1'de verilmiştir 
Çizelge 1. Şanlıurfa ili uzun yıllar ve deneme yılı iklim verileri ortalamaları

Table 1. Sanliurfa province long years and trial year climate data averages

\begin{tabular}{|c|c|c|c|c|c|c|}
\hline & \multirow{2}{*}{$\begin{array}{l}\text { Aylar } \\
\text { Months }\end{array}$} & \multicolumn{3}{|c|}{ Sıcaklık/Temperature $\left({ }^{\circ} \mathrm{C}\right)$} & \multirow{2}{*}{$\begin{array}{l}\text { Yağış miktarı } \\
\text { Precipitation } \\
\quad(\mathrm{mm})\end{array}$} & \multirow{2}{*}{$\begin{array}{l}\text { Oransal nem } \\
\text { Humidity (\%) }\end{array}$} \\
\hline & & Mak. & Min. & $\begin{array}{l}\text { Ortalama } \\
\text { Average }\end{array}$ & & \\
\hline Ocak & 2018 & 14.6 & 4.1 & 4.9 & 14.0 & 62.1 \\
\hline January & UY & 21.6 & 10.6 & 5.5 & 88.3 & 70.5 \\
\hline Şubat & 2018 & 22.7 & -6.8 & 6.5 & 2.6 & 45.6 \\
\hline February & UY & 25.5 & -12.4 & 6.9 & 69.8 & 66.6 \\
\hline Mart & 2018 & 23.9 & 1.5 & 12.7 & 44.0 & 56.8 \\
\hline March & UY & 29.5 & -7.3 & 10.7 & 62.8 & 60.4 \\
\hline Nisan & 2018 & 32.3 & 3.1 & 16.6 & 85.6 & 50.9 \\
\hline April & UY & 36.4 & -3.2 & 16.1 & 49.3 & 55.4 \\
\hline Mayıs & 2018 & 36.5 & 11.5 & 26.9 & 10.2 & 18.2 \\
\hline May & UY & 40.0 & 2.5 & 22.1 & 25.8 & 44.7 \\
\hline Haziran & 2018 & 42.7 & 16.0 & 32.7 & 0.0 & 26.4 \\
\hline June & UY & 44.0 & 8.3 & 28.0 & 3.4 & 32.6 \\
\hline Temmuz & 2018 & 45.0 & 24.3 & 40.2 & 0.0 & 3.7 \\
\hline July & UY & 46.8 & 15.2 & 31.9 & 0.6 & 30.5 \\
\hline Ağustos & 2018 & 46.6 & 24.0 & 36.2 & 0.0 & 28.9 \\
\hline August & UY & 46.2 & 16.0 & 31.3 & 0.8 & 33.3 \\
\hline Eylül & 2018 & 40.0 & 20.0 & 33.6 & 0.0 & 24.6 \\
\hline September & UY & 42.0 & 11.2 & 26.8 & 2.9 & 36.0 \\
\hline Ekim & 2018 & 37.0 & 5.6 & 24.5 & 17.1 & 18.1 \\
\hline October & UY & 37.8 & 2.5 & 20.1 & 25.3 & 46.4 \\
\hline Kasım & 2018 & 25.6 & -3.5 & 11.3 & 29.0 & 43.0 \\
\hline November & UY & 30.8 & -6.0 & 12.8 & 44.5 & 58.8 \\
\hline Aralık & 2018 & 15.1 & -5.0 & 5.5 & 79.6 & 70.3 \\
\hline December & UY & 26.0 & -6.4 & 7.4 & 78.8 & 69.3 \\
\hline Toplam & 2018 & & & & 282.1 & \\
\hline Total & UY & & & & 452.3 & \\
\hline
\end{tabular}

UY: Uzun yıllar/Many years

Çizelge 1'de, 2018 yılı vejetasyon döneminde saptanan iklim değerlerinin uzun yıllar ortalamalarına göre, büyük farklılıklar gösterdiği görülmektedir. Toplam yağış miktarının deneme yılında $282.1 \mathrm{~kg}\left(\mathrm{~m}^{2}\right)^{-1}$, uzun yıllar ortalamasının ise $452.3 \mathrm{~kg}\left(\mathrm{~m}^{2}\right)^{-1}$ olduğu ve toplam yağış miktarının deneme yılında çok daha az düştüğü görülmektedir (Anonim, 2019). Deneme yılında, oransal nem (\%) değerinin genel olarak, uzun yıllar ortalamalarından düşük olduğu ve sıcaklık ortalamalarının, özellikle Mayıs, Haziran, Temmuz, Ağustos, Eylül ve Ekim aylarında, uzun yıllar değerlerinden yüksek olduğu görülmektedir.

Deneme alanı toprakları pH değerinin 7.59, olduğu, kireç, potasyum ve magnezyumca zengin, fosfor oranın düşük ve organik madde ve azotca fakir olduğu belirlenmiştir.

\section{Yöntem}

Fide yetiştirilmek amacıyla ekinezya tohumları, torfla doldurularak ekimi için hazırlanan viyollere, her göze üç adet tohumu olacak şekilde, Mart (2017) ayının ilk haftası elle ekilmiştir. Hazırlanan viyollerin üzeri naylon ile örtülerek fideler, soğuk ve dona karşı korunaklı hale getirilmiştir. Ekimden sora gerekli bakım işlemleri (sulama, havalandırma vb.) ihtiyaca göre yapılmıştır. Ekimden bir hafta sonra viyollerde çıkışlar gözlenmiş ve daha sonra viyollerde tek bitki kalacak şekilde, tekleme yapılmıştır. Bitki isteğine bağlı olarak sulama yapılmıştır.

Dikim için önce, deneme alanı toprak hazırlığı yapılmış ve 2017 Temmuz ayının ilk haftası, sıra arası $70 \mathrm{~cm}$ ve sıra üzeri $30 \mathrm{~cm}$ olacak şekilde açılan ocaklara, tek parsel halinde, fideler elle dikilmiştir. Her sıraya 10 bitki gelecek şekilde, toplam 100 bitki dikimi yapılmıştır. Dikimle beraber, dekara $10 \mathrm{~kg}$ saf Azot ve Fosfor gelecek şekilde, 20-20-0 tabanına gübresi verilmiştir. Dikimden hemen sonra fidelere can suyu verilmiş 
ve toprak nem durumuna göre sulama yapılmıştır. Gerektiğinde yabancı ot mücadelesi elle yapılarak, bitkiler yetiştirilmiştir. Denemenin ilk yılı herhangi bir gözlem alınmamıştır.

Denemenin ikinci yılında da deneme alanındaki yabancı otlar çapa ile temizlenmiştir. 2018 yılında, çıkış döneminde $5 \mathrm{~kg} /$ da ve 1 . biçimden sonra, 5 $\mathrm{kg} \mathrm{da}{ }^{-1}$ saf azot gelecek şekilde, iki defa, Amonyum Nitrat (\%26) gübresi, üst gübre olarak uygulanmıştır. Haftada bir defa sulama uygulanmıştır. Rastgele belirlenen 50 bitkide, mayıs ayından itibaren, ilgili gözlemler alınmıştır. Biçimler, tam çiçeklenme döneminde, bitkilerin ayrı ayrı çiçeklenme durumlarına göre, topraktan $5 \mathrm{~cm}$ yükseklikten, budama makasıyla yapılmıştır.

Rastgele belirlenen bitkilerde ayrı ayrı; sapa kalkma zamanı (gün), ilk tomurcuklanma süresi (gün), tam çiçeklenme süresi (gün), bitki boyu (cm), sap sayısı (adet ocak ${ }^{-1}$ ), yan dal sayısı (adet sap $^{-1}$ ), çiçek sayısı (adet sap ${ }^{-1}$ ), taze herba verimi ( $\mathrm{g}$ bitki ${ }^{-1}$ ), kuru herba verimi ( $\mathrm{g} \mathrm{bitki}^{-1}$ ), kuru sapyaprak-çiçek verimleri (g bitki ${ }^{-1}$ ), taze kök verimi (g bitki ${ }^{-1}$ ), kuru kök verimi (g bitki-1 ${ }^{-1}$, 1. biçimde kuru sap-yaprak-çiçek uçucu yağ oranları (\%) ve uçucu yağ bileşeni dağılımı gözlemleri, Küçükali (2012)'ye göre, belirlenmiştir. Kök ve rozet yaprak gözlemleri vejetasyon sonunda (20.10.2018), 25 bitki sökülerek, alınmıştır.

Uçucu yağ oranları, tüm hasat edilen bitkilerin harmanlanmasıyla elde edilen örneklerde yapılmıştır.

\section{Uçucu yağ bileşenlerinin belirlenmesi}

Kuru sap, yaprak, çiçek ve kökten su buharı distilasyonu ile elde edilen uçucu yağ örnekleri, uçucu yağ bileşenleri analizleri yapılıncaya kadar, derin dondurucuda saklanmıştır.

Uçucu yağ asitleri kompozisyonu analizleri, "Shimadzu Nexis GC-2030" marka Gaz
Kromotografisinde, Kütle Spektroskopisi (MS) dedektörü ve "Teknokroma capilary column TRCN100 (60m X 0.25mm X 0.20um) kapiler kolonu kullanılarak, Harran Üniversitesi Bilim ve Teknoloji Uygulama ve Araştırma Merkezi'nde (HÜBTAM), yapılmıştır. Taşıyıcı gaz olarak helyum (1 mL dakika $^{-1}$ ) kullanılmıştır. Kromatografi cihazı, fırın sıcaklığı $165^{\circ} \mathrm{C} 15 \mathrm{dk}$ tutulmuş, sonra $5^{\circ} \mathrm{C} \mathrm{dk}$ sıcaklık artışı ile $200^{\circ} \mathrm{C}$ ulaşılmış ve 40 dakika bu sıcaklıkta bekletilmiştir. Analizlerde, Hexzanla seyreltilen, uçucu yağ örneklerinden $1 \mu \mathrm{L}$ enjekte edilmiş ve $1 / 20$ split oranı kullanılmıştır. Uçucu yağ asitleri oranları, pik alanlarının oransal dağılımı yüzdesi olarak belirlenmiştir. Analizlerde WILEY, NIST ve REPLIB kütüphaneleri kullanılarak uçucu yağ bileşenleri belirlenmiştir.

\section{Verileri değerlendirilmesi}

Elde edilen verilerin, minimum-maksimum değerleri, genel ortalamaları ve standart sapmaları, Excel paket programı kullanılarak, belirlenmiştir.

\section{Araştırma Bulguları ve Tartışma}

\section{Fenolojik gözlemler}

Denemede bitkilere göre, ikinci yıl çıkışları 1130 Mart 2018 tarihleri, sapa kalkma 9-21 Mayıs 2018 tarihleri, ilk tomurcuklanma 14-28 Mayıs 2018 tarihleri ve ilk tam çiçeklenme 23.06.201830.08.2018 tarihleri arasında gerçekleşmiştir. Çıkış, sapa kalkma, ilk tomurcuklanma ve tam çiçeklenme tarihlerinin bitkilere göre, değişim göstermesi, tohumdan çoğaltılan bitkilerin, genotipik olarak homojen olamamasından kaynaklanmaktadır. Şanlıurfa koşullarında 2018 yılında, E. purpurea'da bitkilere göre saptanan sapa kalkma, ilk tomurcuklanma ve tam çiçeklenme gün sayıları Çizelge 2'de gösterilmiştir. 
Çizelge 2. Şanlıurfa koşullarında, E. purpurea'da bitkilere göre saptanan sapa kalkma, ilk tomurcuklanma ve tam çiçeklenme gün sayısı ortalama ve standart sapma değerleri (gün)

Table 2. Determined average and standard deviation values of the number of days of stem sprouts, first budding and full blooming in E. purpurea in Şanlıurfa conditions.

\begin{tabular}{|c|c|c|c|c|}
\hline & Minimum & Maksimum & $\begin{array}{l}\text { Ortalama } \\
\text { Average }\end{array}$ & $\begin{array}{c}\text { Standart Sapma } \\
\text { Standard Deviation }\end{array}$ \\
\hline $\begin{array}{l}\text { Sapa kalkma (gün) } \\
\text { Stem sprouts (day) }\end{array}$ & 51.00 & 60.00 & 57.46 & \pm 3.87 \\
\hline $\begin{array}{l}\text { Illk tomurcuklanma (gün) } \\
\text { First budding (day) }\end{array}$ & 57.00 & 75.00 & 66.46 & \pm 6.16 \\
\hline \multicolumn{5}{|c|}{ Tam çiçeklenme (gün)/ Full blooming (day) } \\
\hline 1.Biçim/Harvest & 85.00 & 168.00 & 116.86 & \pm 28.08 \\
\hline 2.Biçim/Harvest & 8.00 & 60.00 & 27.56 & \pm 14.92 \\
\hline 3.Biçim/Harvest & 32.00 & 60.00 & 51.50 & \pm 13.26 \\
\hline Ortalama/Average & 67.00 & 96.00 & 65.31 & \pm 18.75 \\
\hline
\end{tabular}

Çizelge 2'de görüldüğü gibi, bitkilere göre sapa kalkma gün sayısı ortalama $57.46 \pm 3.87$ gün olarak, ilk tomurcuklanma gün sayısı ortalama $66.46 \pm 6.16$ gün olarak ve biçimlere göre tam çiçeklenme gün sayısı, 1 . Biçimde ortalama $116.86 \pm 28.08$ gün, 2. Biçimde ortalama 27.56 \pm 14.92 gün, 3. Biçimde ortalama $51.50 \pm 13.26$ gün olarak saptanmıştır. Bitkilere göre sapa kalkma, ilk tomurcuklanma ve tam çiçeklenme gün sayısı değerleri arasında farklılıklar saptanmıştır. Genel olarak, tam çiçeklenme gün sayıları yönünden biçimler arasında büyük farklılıklar gözlenmiştir. Birinci biçimden sonra, bitkilerden sadece 16 tanesinde yeniden çiçeklenme olmuş ve bunlardan ikinci biçimler alınmıştır. İkinci biçim alınan bitkilerden ise, sadece 6 adedi tekrar çiçeklenmiştir. Dolayısıyla, çalışmaya konu olan 50 bitkiden 34 tanesinden bir biçim, 10 tanesinden iki biçim ve altı tanesinden de üç biçim alınabilmiştir. İlk çiçeklenme süresi uzun süren bitkilerde, tekrar çiçeklenme gözlenmemiş ve tek biçim alınmıştır. Bu durum, genotipik farklılıktan, farklı genotipli bitkilerin artan sıcaklık ve güneşlenme süresine (Çizelge 1), farklı tepki vermelerinden kaynaklanmış olabilir. Nitekim, Küçükali (2012) ekinezyanın bir uzun gün bitkisi olduğu ve Çukurova koşullarında uzun günlerde çiçeklendiğini bildirilmektedir.

\section{Bitkisel özellikler}

Şanlıurfa koşullarında, biçimlere göre, $E$. purpurea bitkilerinde saptanan bitki boyu, sap sayısı, yan dal sayısı ve çiçek sayısı minimum, maksimum, ortalama ve standart sapma değerleri Çizelge 3 'te verilmiştir.

Çizelge 3'te görüldüğü gibi, E. purpurea'da vejetasyon süresince toplam 4 hasat yapılabilmiştir. Bitki boylarının, 1. Biçimde ortalama $39.16 \pm 15.98 \mathrm{~cm}$ olduğu, 2. Biçimde ortalama $31.50 \pm 16.47 \mathrm{~cm}$ olduğu, 3. Biçimde ortalama $22.00 \pm 20.81 \mathrm{~cm}$ olduğu ve kök hasadında ortalama $14.80 \pm 17.67 \mathrm{~cm}$ olduğu; sap sayısı değerlerinin, 1. Biçimde ortalama $1.44 \pm 0.88$ adet ocak $^{-1}$ olduğu, 2. Biçimde ortalama $1.25 \pm 0.68$ adet ocak $^{-1}$ olduğu, 3. Biçimde ortalama 1.00 adet ocak $^{-1}$ olduğu ve kök hasadında sap oluşmadığı; yan dal sayısı değerlerinin, 1. Biçimde ortalama $3.62 \pm 2.75$ adet $\operatorname{sap}^{-1}$ olduğu, 2. Biçimde ortalama $2.75 \pm 1.17$ adet sap $^{-1}$ olduğu, 3. ve 4 . hasat dönemimde bitkide yan dal oluşmadığı; çiçek sayısı değerlerinin, 1 . Biçimde ortalama $3.52 \pm 4.03$ adet bitki ${ }^{-1}$ olduğu, 2. Biçimde ortalama $2.19 \pm 2.04$ adet bitki ${ }^{-1}$ olduğu, 3. Biçimde ortalama $1.00 \pm 0$ adet bitki ${ }^{-1}$ olduğu ve kök hasadında çiçeklenme olmadığı belirlenmiştir.

Bitki boyu, sap sayısı, yan dal sayısı ve çiçek sayısı yönünden bitkiler arasında ve biçimler arasında büyük oranda farklılıklar saptanmıştır. Genel olarak, geciken biçimlerde bitki boyu, sap sayısı, yan dal sayısı ve çiçek sayısı azalmıştır. Bitkiler arasındaki büyük farklılık, tohumla çoğaltılan bitkilerin genotipik olarak homojen olmadığının bir göstergesidir ve bundan kaynaklanabilir. Biçim sıralarındaki farklılık ise, bitkinin yetişme dönemlerinde maruz kaldığı iklim 
koşulları farklıığından kaynaklanabilir. Nitekim, deneme alanı iklim değerleri (Çizelge 1) incelendiğinde geciken biçimlerde havanın daha sıcak ve kurak olduğu gözlenmektedir.

Bitki boyu değerlerimiz, bazı araştırıcıların (Özcan, 2014; Ulutaş, 2016) bildirdiği değerlerden (60-102 cm) düşük bulunmuştur. Sap sayısı incelendiğinde, bulgularımızın Özcan (2014) bildirdiği değerlere (2.10-4.12 adet ocak $\left.{ }^{-1}\right)$ benzer,
Küçükali (2012) bildirdiği değerlerden (2.07-2.47 adet ocak $^{-1}$ ) düşük olduğu görülmektedir. Çiçek sayısı değerlerimizin ise, Özcan (2014)'ın bildirdiği değerlere (1.77-5.24 adet bitki ${ }^{-1}$ ) benzer, bazı araştırıcıların (Küçükali, 2012; Ulutaş, 2016) bildirdiği değerlerden (13.03-47.00 adet bitki ${ }^{-1}$ ) düşük olduğu saptanmıştır. Bu durum ekolojik farklılıklardan, bitki yaşından ve yetiştirme tekniğinden kaynaklanabilir.

Çizelge 3. Şanlıurfa koşullarında, E. purpurea'da, bitkilerinde saptanan bitki boyu, sap sayısı, yan dal sayısı ve çiçek sayısı ortalama ve standart sapma değerleri.

Table 3. Determined average and standard deviation values of the plant height, number of stems, number of branches and number of flowers in E. purpurea in Şanlıurfa conditions.

\begin{tabular}{|c|c|c|c|c|c|}
\hline $\begin{array}{l}\text { Biçim sırası } \\
\text { Harvest number }\end{array}$ & $\begin{array}{c}\text { Örnek sayısı } \\
\text { Number of } \\
\text { samples } \\
\text { observed }\end{array}$ & Minimum & Maksimum & $\begin{array}{l}\text { Ortalama } \\
\text { Average }\end{array}$ & $\begin{array}{l}\text { Standart sapma } \\
\text { Standard deviation }\end{array}$ \\
\hline \multicolumn{6}{|c|}{ Bitki Boyu/Plant Height (cm) } \\
\hline 1.Biçim/Harvest & 50 & 10.00 & 70.00 & 39.16 & \pm 15.98 \\
\hline 2.Biçim/Harvest & 16 & 5.00 & 70.00 & 31.50 & \pm 16.47 \\
\hline 3.Bçim/Harvest & 6 & 10.00 & 64.00 & 22.00 & \pm 20.81 \\
\hline $\begin{array}{l}\text { Kök hasadı/ } \\
\text { Root harvest }\end{array}$ & 25 & 10.00 & 40.00 & 14.80 & \pm 17.67 \\
\hline $\begin{array}{c}\text { Ortalama } \\
\text { Average }\end{array}$ & 24.25 & 8.75 & 61.00 & 26.87 & \pm 17.73 \\
\hline \multicolumn{6}{|c|}{ Sap sayısı (adet ocak ${ }^{-1}$ )/Number of stems (number plant ${ }^{-1}$ ) } \\
\hline 1.Biçim/Harvest & 50 & 1.00 & 5.00 & 1.44 & \pm 0.88 \\
\hline 2.Biçim/Harvest & 15 & 1.00 & 3.00 & 1.25 & \pm 0.68 \\
\hline $\begin{array}{l}\text { 3.Biçim/Harvest } \\
\text { Kök hasadı/ } \\
\text { Root harvest }\end{array}$ & $\begin{array}{l}6 \\
-\end{array}$ & $\begin{array}{r}1.00 \\
-\end{array}$ & $\begin{array}{r}1.00 \\
-\end{array}$ & $\begin{array}{r}1.00 \\
-\end{array}$ & \pm 0.00 \\
\hline $\begin{array}{l}\text { Ortalama } \\
\text { Average }\end{array}$ & 17.75 & 1.00 & 3.00 & 1.23 & \pm 0.78 \\
\hline \multicolumn{6}{|c|}{ Yan dal sayısı (adet sap ${ }^{-1}$ )/Number of branches (number stem ${ }^{-1}$ ) } \\
\hline 1.Biçim/Harvest & 50 & 1.00 & 16.00 & 3.62 & \pm 2.75 \\
\hline $\begin{array}{l}\text { 2.Biçim/Harvest } \\
\text { 3.Biçim/Harvest } \\
\text { Kök hasadı/ } \\
\text { Root harvest }\end{array}$ & 8 & 2.00 & 5.00 & 2.75 & \pm 1.17 \\
\hline $\begin{array}{l}\text { Ortalama } \\
\text { Average }\end{array}$ & 29 & 1.00 & 7.00 & 3.19 & \pm 1.95 \\
\hline \multicolumn{6}{|c|}{ Çiçek sayısı (adet bitki $\left.{ }^{-1}\right) /$ Number of flowers (number plant ${ }^{-1}$ ) } \\
\hline 1.Biçim/Harvest & 50 & 1.00 & 23.00 & 3.52 & \pm 4.03 \\
\hline 2.Biçim/Harvest & 16 & 1.00 & 9.00 & 2.19 & \pm 2.04 \\
\hline $\begin{array}{l}\text { 3.Biçim/Harvest } \\
\text { Kök hasadı/ } \\
\text { Root harvest }\end{array}$ & $\begin{array}{l}6 \\
-\end{array}$ & $\begin{array}{r}1.00 \\
-\end{array}$ & $\begin{array}{r}1.00 \\
-\end{array}$ & $\begin{array}{r}1.00 \\
-\end{array}$ & \pm 0 \\
\hline $\begin{array}{l}\text { Ortalama } \\
\text { Average }\end{array}$ & 24 & 1.00 & 11.00 & 2.22 & \pm 3.04 \\
\hline
\end{tabular}

\section{Verimi değerleri}

E. purpurea'da bitkilere göre, farklı biçimlerde saptanan bitki başına taze herba verimi, kuru herba verimi, kuru çiçek verimi, kuru yaprak verimi ve kuru sap verimi minimum, maksimum, ortalama ve standart sapma değerleri Çizelge 4 'te verilmiştir. 
Çizelge 4. Şanlıurfa koşullarında, E. purpurea'da, taze herba verimi, kuru herba verimi, kuru çiçek verimi, kuru yaprak verimi ve kuru sap verimi ortalama ve standart sapma değerleri.

Table 4. Determined average and standard deviation values of the fresh herb yield, dry herb yield, dry flower yield, dry leaf yield and dry stem yield in E. purpurea in Şanlıurfa conditions.

\begin{tabular}{|c|c|c|c|c|c|}
\hline $\begin{array}{c}\text { Biçim sırası } \\
\text { Harvest number }\end{array}$ & $\begin{array}{c}\text { Örnek sayısı } \\
\text { Number of } \\
\text { samples } \\
\text { observed }\end{array}$ & Minimum & Maksimum & $\begin{array}{l}\text { Ortalama } \\
\text { Average }\end{array}$ & $\begin{array}{l}\text { Standart sapma } \\
\text { Standard deviation }\end{array}$ \\
\hline \multicolumn{6}{|c|}{ 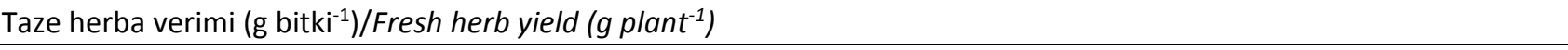 } \\
\hline 1.Biçim/Harvest & 50 & 1.60 & 183.1 & 36.06 & \pm 50.78 \\
\hline 2.Biçim/Harvest & 15 & 1.00 & 63.18 & 21.80 & \pm 20.53 \\
\hline 3.Biçim/Harvest & 6 & 2.10 & 13.35 & 8.49 & \pm 5.00 \\
\hline $\begin{array}{l}\text { Kök hasadı/ } \\
\text { Root Harvest }\end{array}$ & 25 & 8.73 & 101.85 & 48.28 & \pm 22.90 \\
\hline $\begin{array}{l}\text { Ortalama } \\
\text { Average }\end{array}$ & 24 & 2.9575 & 44.595 & 28.79 & \pm 19.67 \\
\hline \multicolumn{6}{|c|}{ Kuru herba verimi $\left(\mathrm{g} \mathrm{bitki}^{-1}\right) /$ Dry herb yield $\left(\mathrm{g}\right.$ plant $\left.^{-1}\right)$} \\
\hline 1.Biçim/Harvest & 50 & 0.80 & 69.76 & 8.95 & \pm 12.91 \\
\hline 2.Biçim/Harvest & 17 & 0.10 & 18.23 & 6.41 & \pm 5.81 \\
\hline 3.Bçim/Harvest & 6 & 0.60 & 3.40 & 2.35 & \pm 1.15 \\
\hline $\begin{array}{l}\text { Kök hasadı/ } \\
\text { Root harvest }\end{array}$ & 25 & 2.66 & 35.74 & 15.39 & \pm 7.90 \\
\hline $\begin{array}{c}\text { Ortalama } \\
\text { Average }\end{array}$ & 24.5 & 1.04 & 31.78 & 8.28 & \pm 6.94 \\
\hline \multicolumn{6}{|c|}{ Kuru çiçek verimi (g bitki $\left.{ }^{-1}\right) /$ Dry flower yield (g plant ${ }^{-1}$ ) } \\
\hline 1.Biçim/Harvest & 50 & 0.014 & 17.79 & 2.56 & \pm 3.13 \\
\hline 2.Biçim/Harvest & 17 & 0.10 & 8.64 & 2.05 & \pm 2.08 \\
\hline 3.Biçim/Harvest & 6 & 0.40 & 2.40 & 1.43 & \pm 0.68 \\
\hline $\begin{array}{l}\text { Kök hasadı/ } \\
\text { Root Harvest }\end{array}$ & - & - & - & - & \\
\hline $\begin{array}{l}\text { Ortalama } \\
\text { Average }\end{array}$ & 24.33 & 0.17 & 9.61 & 2.01 & \pm 1.97 \\
\hline \multicolumn{6}{|c|}{ Kuru yaprak verimi (g bitki $\left.{ }^{-1}\right) /$ Dry leaf yield $\left(g\right.$ plant $^{-1}$ ) } \\
\hline 1.Biçim/Harvest & 50 & 0.005 & 22.54 & 3.19 & \pm 4.46 \\
\hline 2.Biçim/Harvest & 15 & 0.40 & 9.16 & 2.38 & \pm 2.61 \\
\hline 3.Biçim/Harvest & 12 & 0.60 & 1.10 & 0.52 & \pm 0.38 \\
\hline $\begin{array}{l}\text { Kök hasadı/ } \\
\text { Root Harvest }\end{array}$ & - & - & - & - & \\
\hline $\begin{array}{l}\text { Ortalama } \\
\text { Average }\end{array}$ & 25.67 & 0.34 & 10.93 & 2.03 & \pm 2.48 \\
\hline \multicolumn{6}{|c|}{ Kuru sap verimi $\left(\mathrm{g} \mathrm{bitki}^{-1}\right) /$ Dry stem yield $\left(\mathrm{g} \mathrm{plant}^{-1}\right)$} \\
\hline 1.Biçim/Harvest & 50 & 1.38 & 132.86 & 36.60 & \pm 50.78 \\
\hline 2.Biçim/Harvest & 16 & 0.10 & 6.98 & 1.97 & \pm 2.14 \\
\hline $\begin{array}{l}\text { 3.Biçim/Harvest } \\
\text { Kök hasadı/ } \\
\text { Root Harvest }\end{array}$ & $\begin{array}{l}6 \\
-\end{array}$ & $\begin{array}{c}0.20 \\
-\end{array}$ & $\begin{array}{c}0.60 \\
-\end{array}$ & $\begin{array}{c}0.35 \\
-\end{array}$ & \pm 0.15 \\
\hline $\begin{array}{l}\text { Ortalama } \\
\text { Average }\end{array}$ & 24 & 0.56 & 46.81 & 12.97 & \pm 17.69 \\
\hline
\end{tabular}

Çizelge 4'te görüldüğü gibi, taze herba verim değerlerinin, 1. Biçimde ortalama $36.06 \pm 50.78 \mathrm{~g}$ bitki $^{-1}$ olduğu, 2. Biçimde ortalama $21.80 \pm 20.53 \mathrm{~g}$ bitki $^{-1}$ olduğu, 3. Biçimde ortalama $8.49 \pm 5.00 \mathrm{~g}$ bitki $^{-1}$ olduğu ve kök hasadında ortalama $48.28 \pm 22.90 \mathrm{~g} \mathrm{bitki}^{-1}$ olduğu; kuru herba veriminin 1. Biçimde ortalama $8.95 \pm 12.91 \mathrm{~g} \mathrm{bitki}^{-1}$ olduğu, 2 . Biçimde ortalama $6.41 \pm 5.81 \mathrm{~g} \mathrm{bitki}^{-1}$ olduğu, 3 . Biçimde ortalama $2.35 \pm 1.15 \mathrm{~g} \mathrm{bitki}^{-1}$ olduğu ve kök hasadında ortalama $15.39 \pm 7.90 \mathrm{~g}$ bitki $^{-1}$ olduğu; kuru çiçek verimi değerlerinin 1. Biçimde ortalama $2.56 \pm 3.13 \mathrm{~g} \mathrm{bitki}^{-1}$ olduğu, 2. Biçimde ortalama $2.05 \pm 2.08 \mathrm{~g} \mathrm{bitki}^{-1}$ olduğu, 3. Biçimde ortalama $1.43 \pm 0.68 \mathrm{~g} \mathrm{bitki}^{-1}$ olduğu; kuru yaprak verimi değerlerinin 1. Biçimde ortalama $3.19 \pm 4.46$ g bitki ${ }^{-1}$ olduğu, 2. Biçimde ortalama $2.38 \pm 2.61 \mathrm{~g}$ bitki $^{-1}$ olduğu, 3. Biçimde ortalama $0.52 \pm 0.38 \mathrm{~g}$ bitki $^{-1}$ olduğu; kuru sap verimi değerlerinin 1. 
Biçimde ortalama $36.6 \pm 50.78 \mathrm{~g} \mathrm{bitki}^{-1}$ olduğu, 2 . Biçimde ortalama $1.97 \pm 2.14 \mathrm{~g} \mathrm{bitki}^{-1}$ olduğu, 3 . Biçimde ortalama $0.35 \pm 0.15 \mathrm{~g} \mathrm{bitki}^{-1}$ olduğu belirlenmiştir. Taze herba verimi, kuru herba verimi, kuru çiçek verimi, kuru yaprak verimi ve kuru sap verimi değeri yönünden bitkiler arasında ve biçimler arasında büyük oranda farklılıklar saptanmıştır. Genel olarak, incelenen tüm özelliklerde en yüksek ortalama değerler 1 . Biçimden elde edilmiştir. Geciken biçimlerde taze herba verimi, kuru herba verimi, kuru çiçek verimi, kuru yaprak verimi ve kuru sap verimi değeri azalmıştır. Bitkiler arasındaki büyük farklılık, tohumla çoğaltılan bitkilerin genotipik olarak homojen almadığının bir göstergesidir ve bundan kaynaklanabilir. Biçimler arasındaki farklılıklar, bitkinin yetişme dönemlerinde maruz kaldığı iklim koşullarından kaynaklanabilir. Deneme alanı iklim değerleri incelendiğinde, geciken biçimlerde havanın daha sıcak ve kurak olduğu gözlenmektedir. Sıcakların artışıyla ve bitki gelişimi azalmış ve bu durum geciken biçimlerde verimlerde düşme olarak kendini göstermiştir. Benzer bulguları Özcan (2014), ekinezyada düşük sıcaklıkların bitkilerin gelişimine olumlu, artan sıcaklıkların ise bitkilerin gelişimine olumsuz etkilediğini, belirtmiştir.

Verimi değerlerimiz, genel olarak bazı araştırıcıların (Küçükali, 2012; Yeşil ve Kan, 2013; Ulutaş, 2016) bildirdikleri değerlerden düşük bulunmuştur. $\mathrm{Bu}$ durum, bitki yetiştirtme teknikleri, bitki yaşı ve bölge koşulları farklılığından kaynaklanabilir.

\section{Taze kök verimi}

E. purpurea'da kök verimi için sökülen 25 bitkide saptanan, taze ve kuru kök verimi minimum, maksimum, ortalama ve standart sapma değerleri Çizelge 5 'te verilmiştir.

Çizelge 5. Şanlıurfa koşullarında, E. purpurea'da taze ve kuru kök verimi ortalama ve standart sapma değerleri.

Table 5. Determined average and standard deviation values of the fresh root yield and dry root yield in E. purpurea in Şanlıurfa conditions.

\begin{tabular}{|c|c|c|c|c|}
\hline & Minimum & Maksimum & $\begin{array}{l}\text { Ortalama } \\
\text { Average }\end{array}$ & $\begin{array}{c}\text { Standart sapma } \\
\text { Standard deviation }\end{array}$ \\
\hline $\begin{array}{l}\left.\text { Taze kök verimi (g bitki }{ }^{-1}\right) \\
\left.\text { Fresh root yield (g plant }{ }^{-1}\right)\end{array}$ & 4.78 & 94.85 & 36.54 & \pm 20.21 \\
\hline $\begin{array}{l}\text { Kuru kök verimi (g bitki }{ }^{-1} \text { ) } \\
\text { Dry root yield (g plant }{ }^{-1} \text { ) }\end{array}$ & 1.35 & 35.73 & 12.20 & \pm 7.04 \\
\hline
\end{tabular}

Çizelge 5'te, bitkide taze kök verimi değerlerinin $36.54 \pm 20.21 \mathrm{~g} \mathrm{bitki}^{-1}$ olduğu ve kuru kök verimi değerlerinin ise ortalama $12.20 \pm 7.04 \mathrm{~g}$ bitki ${ }^{-1}$ olduğu görülmektedir. Taze ve kuru kök verimi değeri yönünden bitkiler arasında büyük farklılıklar gözlenmiştir. Bitkiler arasındaki bu farklılık, tohumdan çoğaltılan bitkilerin genotipik olarak homojen almadığının bir göstergesidir ve bundan kaynaklanabilir.

Kök verimi değerlerimiz, genel olarak bazı araştırıcıları (Küçükali, 2012; Özcan, 2014) bildirdikleri değerlerden düşük bulunmuştur. Bu durum, bitki yetiştirtme teknikleri, bitki yaşı ve bölge koşulları farklılığından kaynaklanabilir.

Uçucu yağ oranı ve bileşenleri

Denemede E. purpurea bitkisinde 1. Biçimde farklı organlarda saptanan ortalama uçucu yağ oranı ve uçucu yağ bileşenleri oransal dağılım değerleri (\%) Çizelge 6'da verilmiştir. 
Çizelge 6. E. purpurea'da, farklı organlarda saptanan, ortalama uçucu yağ oranı ve uçucu yağ bileşenleri dağılımı. Table 6. Determined average essential oil ratio and distribution of essential oil components from different organs in E. purpurea in Şanlıurfa conditions.

\begin{tabular}{|c|c|c|c|c|c|c|}
\hline & \multirow{2}{*}{$\begin{array}{c}\text { Çıkış } \\
\text { Zamanı } \\
\text { R. Time }\end{array}$} & \multicolumn{5}{|c|}{ Pik Alanı/Peak Area (\%) } \\
\hline & & $\begin{array}{l}\text { Yaprak } \\
\text { Leaf }\end{array}$ & $\begin{array}{c}\text { Rozet } \\
\text { Yaprak } \\
\text { Rosette Leaf }\end{array}$ & $\begin{array}{l}\text { Sap } \\
\text { Stem }\end{array}$ & $\begin{array}{l}\text { Çiçek } \\
\text { Flower }\end{array}$ & $\begin{array}{l}\text { Kök } \\
\text { Root }\end{array}$ \\
\hline $\begin{array}{l}\text { Uçucu yağ oranı } \\
\text { Essential Oil Ratio (\%) }\end{array}$ & & 0.04 & 0.04 & 0.03 & 0.04 & 0.03 \\
\hline \multicolumn{7}{|l|}{ Bileşen Adı/Component Name } \\
\hline Alpha-Pinene & 11.489 & - & 0.42 & 8.20 & 7.47 & 0.65 \\
\hline Camphene & 12.180 & - & - & 0.41 & - & - \\
\hline 3-Hexyl Hydroperoxide & 12.323 & 10.52 & 5.51 & 1.59 & 10.14 & 10.06 \\
\hline Verbenene & 12.458 & - & - & 0.30 & - & \\
\hline 2-Hexyl Hydroperoxide & 12.792 & 14.61 & 5.49 & 1.91 & 11.28 & 10.19 \\
\hline 3-Hexen-2-One & 13.297 & - & - & - & - & 1.82 \\
\hline Cyclohexyl Methyl Ketone & 13.296 & - & - & - & 1.15 & - \\
\hline Sabinene & 13.410 & - & 0.68 & 0.53 & - & 0.89 \\
\hline (-)-Beta-Pinene & 13.542 & - & - & 1.09 & 1.29 & 1.63 \\
\hline Myrcene & 14.350 & - & - & - & - & 0.54 \\
\hline Beta-Myrcene & 14.407 & - & 1.49 & 3.38 & - & - \\
\hline Alpha-Phellandrene & 14.954 & - & - & - & 3.74 & \\
\hline P-Cymene & 16.039 & - & 1.13 & 0.49 & 3.52 & 1.57 \\
\hline Limonene & 16.181 & - & - & 1.74 & 1.59 & - \\
\hline Isopropylaniline & 19.118 & 1.22 & - & & - & - \\
\hline N-Ethyl-P-Toluidine & 19.150 & - & - & - & 1.26 & \\
\hline Linalool & 19.907 & - & 0.76 & - & - & - \\
\hline Alpha-Campholenic Aldehyde & 21.135 & - & - & 1.98 & - & - \\
\hline $\begin{array}{l}\text { 6-Isopropenyl-3-Methoxymethoxy-3- } \\
\text { Methyl-Cyclohexene }\end{array}$ & 21.479 & - & - & 0.83 & - & - \\
\hline Pinocarveol & 21.784 & 2.50 & - & 2.35 & 1.70 & - \\
\hline (-)-Cis-Verbenol & 21.906 & 2.95 & - & 1.26 & 1.20 & - \\
\hline Verbenol & 22.094 & 11.62 & - & 6.65 & 4.90 & 1.08 \\
\hline P-Mentha-1,5-Dien-8-Ol & 22.311 & - & - & 0.63 & - & - \\
\hline 2,6-Dimethylocta-1,5,7-Trien-3-OI & 22.760 & - & - & 0.29 & - & - \\
\hline Pinocarvone & 22.970 & - & - & 0.52 & - & - \\
\hline P-Mentha-1,5-Dien-8-OI & 23.245 & - & - & 0.52 & - & - \\
\hline Terpinen-4-OI & 23.750 & - & - & 0.71 & - & - \\
\hline P-Cymen-8-Ol & 24.151 & 1.18 & - & 0.78 & - & - \\
\hline 1,5-Heptadiene, 3,3-Dimethyl-, (E)- & 24.336 & - & - & 0.47 & - & - \\
\hline 1-Alpha-Terpinyl Acetate & 24.435 & - & - & 0.34 & - & - \\
\hline D-Myrtenal & 24.670 & - & - & 1.57 & - & - \\
\hline Myrtenol & 24.720 & - & & 1.06 & - & - \\
\hline Verbenone & 25.276 & 5.25 & - & 1.55 & 1.81 & - \\
\hline Trans-Carveol & 25.835 & 1.29 & - & - & - & - \\
\hline Cis-Carveol & 25.839 & - & - & 1.23 & - & - \\
\hline Carvone & 27.016 & - & - & 0.61 & - & - \\
\hline Linalyl Acetate & 27.674 & - & 0.94 & - & - & - \\
\hline Carvacrol & 29.900 & 1.96 & 14.07 & 0.35 & - & - \\
\hline Beta. Bourbonene & 33.800 & - & 1.19 & - & - & - \\
\hline Beta-Elemene & 34.025 & - & - & 0.31 & - & 0.86 \\
\hline Caryophyllene & 35.336 & - & 3.32 & 1.11 & 1.80 & 3.33 \\
\hline Germacrene-D & 35.758 & - & 0.67 & - & 6.70 & - \\
\hline Trans-Alpha-Bergamotene & 35.956 & - & - & 0.56 & - & - \\
\hline Alpha-Humulene & 36.843 & - & 2.18 & 0.37 & - & 0.92 \\
\hline 1,13-Tetradecadiene & 37.473 & - & - & - & - & 2.18 \\
\hline Germacrene-D & 37.951 & 1.07 & 50.65 & 3.31 & - & 42.19 \\
\hline (E)-Beta-Farnesene & 38.091 & - & - & 0.26 & - & - \\
\hline Tetradecan-1-Ol & 38.284 & - & - & - & - & 0.59 \\
\hline Cubedol & 38.549 & - & - & 0.27 & - & - \\
\hline T-Muurolol & 38.563 & - & - & - & 1.58 & \\
\hline
\end{tabular}




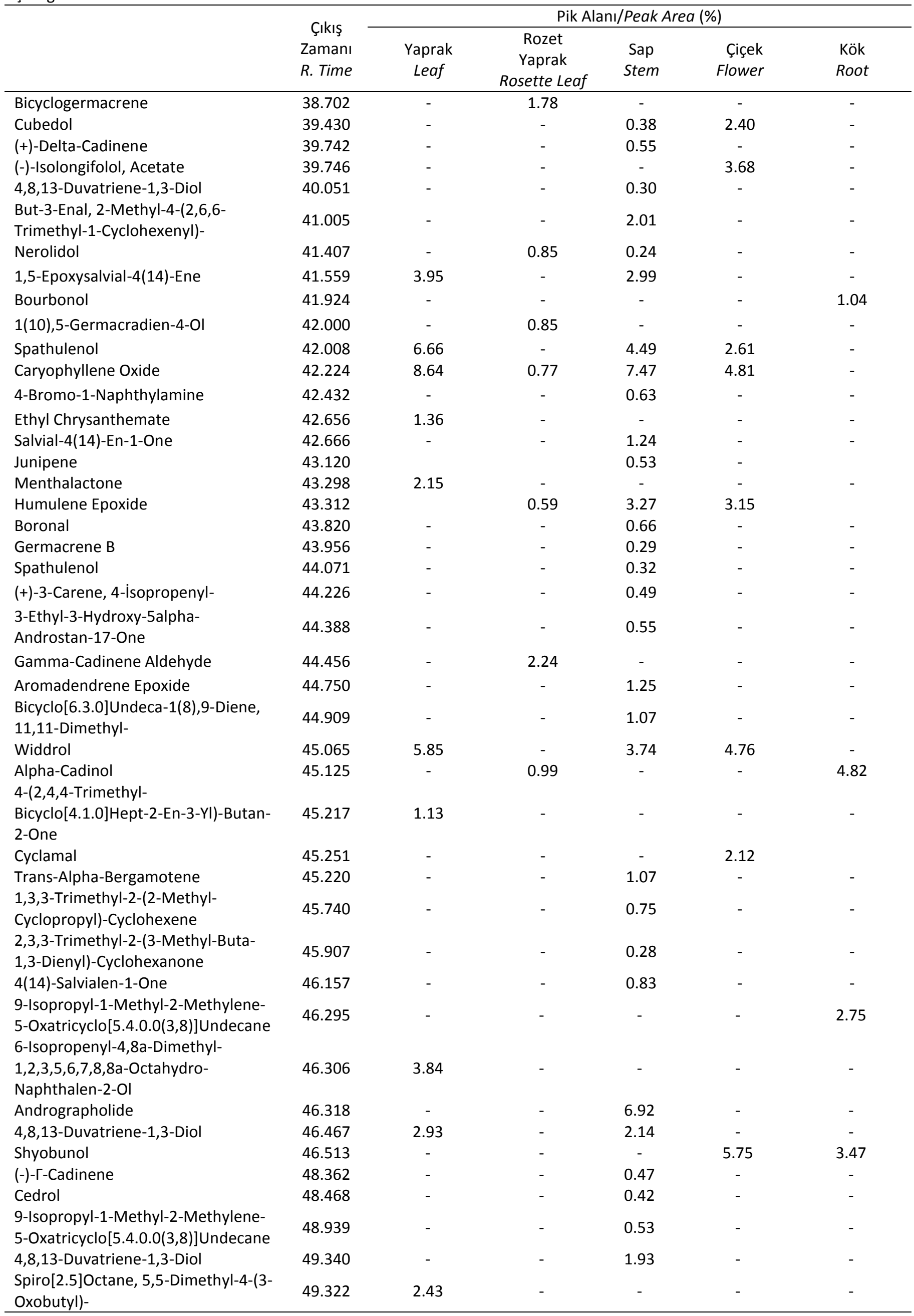




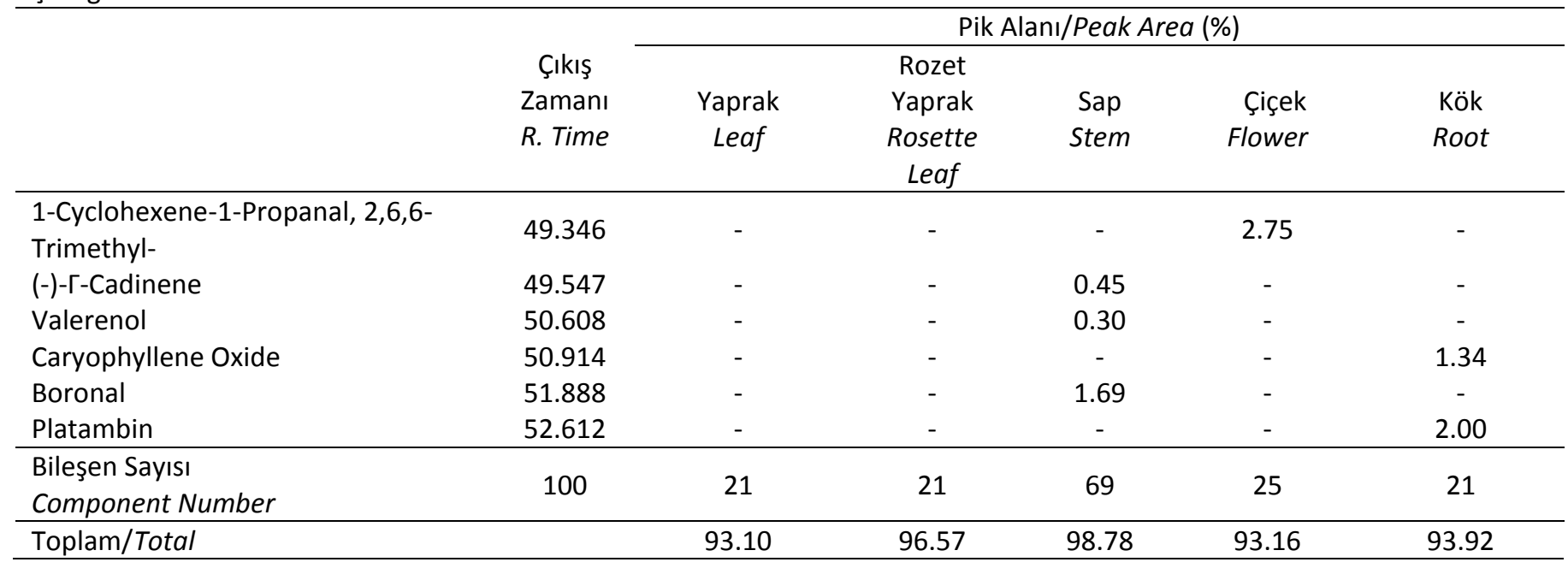

Çizelge 6'da görüldüğü gibi, ortalama uçucu yağ oranı değerlerinin kuru yaprakta \%0.04, kuru sapta \%0.03 ve kuru çiçekte \%0.04 ayrıca, kök hasadından elde edilen, rozet yaprakta \%0.04 ve kökte \%0.03 olduğu belirlenmiştir.

Uçucu yağ oranına ilişkin değerlerimiz bazı araştırıcıların (Küçükali, 2012; Ulutaş, 2016) bildirdikleri değerlerde düşük bulunmuştur. Bilindiği gibi, bitkilerde uçucu yağ birikimi, bitki ve çevre şartlarına bağlı olarak değişmektedir. Diğer bir ifadeyle, türlerin genetik yapısı, yetiştiği iklim koşulları, uygulanan agronomik işlemler ve bitkinin yaşı uçucu yağ birikiminde önemlidir (Sangwan ve ark. 2001). Bu farklılık ekolojik koşullar, genotip, bitki yaşı ve yetiştirme tekniğinden kaynaklanabilir.

Çizelge 6 incelendiğinde, yaprak uçucu yağında tüm bileşenlerin \%93.10'nu oluşturan 21 bileşen, rozet yaprak uçucu yağında tüm bileşenlerin \%96.57'sini oluşturan 21 bileşen, sap uçucu yağında tüm bileşenlerin \%99.78'ini oluşturan 69 bileşen, çiçek uçucu yağında \%93.16'sını oluşturan 25 bileşen ve kök uçucu yağında \%93.92 oluşturan 21 bileşen saptandığı görülmektedir. Ayrıca, yaprak uçucu yağının ana bileşeninin 2-hexyl hydroperoxide (\%14.61) olduğu ve bunu verbenol (\%11.62), 3-Hexyl hydroperoxide (\%10.52) ve Caryophyllene oxide (\%8.64) izlendiği saptanmıştır. Rozet yaprak uçucu yağında en yüksek oranda germacrene-D (\%50.65) olduğu ve bunu carvacrol'un (\%14.07) takip ettiği; kuru sap uçucu yağında ana bileşen olarak \%8.20 oranında alpha-pinene ve \%7.47 oranında caryophyllene oxide; çiçek uçucu yağında ana bileşen olarak \%11.28 oranında 2-hexylhydroperoxide olduğu ve bunu \%10.14 ile 3-hexyl Hydroperoxide, \%7.47 ile alpha-pinene, \%6.70 ile germacrene-D ve \%5.75 ile shyobunol'un takip ettiği ve kök uçucu yağında ana bileşen olarak \%42.19 germacrene- $D$ ve bunu \%10.19 ile 2-hexylhydroperoxide ve \%10.06 ile 3hexylhydroperoxide bileşeninin takip ettiği görülmektedir.

Bulgularımız, E. purpurea sap ve çiçeklerinde alpha-pinene'in ana bileşenler olduğunu bildiren Ulutaş (2016)'ın bulgularıyla kısmen uyumlu görülmüştür. Çiçek uçucu yağında ana bileşen olarak 2-hexylhydroperoxide saptanmış, alphapinene üçüncü sırada yer almıştır. Bu farklılık ekolojik koşullardan, genotipten veya yetiştirme tekniğinden kaynaklandığı düşünülebilir. Bauer (1998) ekinezya uçucu yağ bileşenlerinin organlara ve analiz yöntemine göre değişebileceğini bildirmektedir. Bulgularımı, yapraklarda germacrene $D^{\prime}$ nin ana bileşen olduğunu bildiren bazı araştırıcıların (Özcan, 2014; Ulutaş, 2016) bulgularıyla ise uyumlu bulunmuştur.

\section{Sonuç ve Öneriler}

Sonuç olarak, Harran Ovası koşullarında $E$. purpurea'dan toplam 3 biçim alınabilecek genotiplerin olduğu, her ne kadar verim değerlerinin literatür bulgularına göre düşük olduğu gözlense de ekolojik koşullara uygun genotipler ve yetiştirme teknikleriyle, ekinezyanın 
Şanlıurfa koşullarında yetiştirilme potansiyelinin bulunduğu söylenebilir. Bu nedenle, bölge koşullularına uygun çeşitlerin belirlenmesi veya ıslah çalışmaları yapılarak, bölge koşullarına uygun çeşit geliştirilmesi gerekmektedir. Ayrıca, bölge koşullarında uygun yetiştirme tekniklerinin (ekim zamanı, hasat zamanı, bitki sıklığı, gübreleme çeşitleri, sulama şekilleri) belirlenmesi gerekmektedir.

\section{Ekler}

Bu çalışma, HÜBAK Tarafından Desteklenen (Proje No: 19126), Yüksek Lisans Tezinden hazırlanmıştır.

\section{Çıkar Çatışması Beyanı: Makale yazarları} aralarında herhangi bir çıkar çatışması olmadığını beyan ederler.

Yazar Katkısı: AÖ çalışmayı tasarlayarak denemeleri kurmuş, MS çalışmayı yürütmüş, AÖ verileri analiz etmiş, AÖ ve MS makaleyi yazmıştır.

\section{Kaynaklar}

Adam, K. (2002). Echinacea As an Alternative Crop. Horticulturel Technical Note. www Attra.ncat.org. (Erişim Tarihi: 01.04.2019).

Anonim (2019). Şanlıurfa meteoroloji istasyon verileri. Devlet Meteoroloji İşleri Müdürlügü̈, Şanlıurfa.

Bauer, R. (1998). Echinacea: Biological effects and active principles. In Phytomedicines of Europe, Chemistry and Biological Activity, edited by L.D., Lawson and R. Bauer, pp. 140-157. Washington, DC: American Chemical Society.

Bruneton, J. (1999). Pharmacognosy, Phytochemistry, Medicinal Plants. 2nd Ed., Paris: Lavoisier,173-175p.

Chen, C. L., Zhang, S.C. \& Sung, J.M. (2008). Biomass and caffeoyl phenols production of Echinacea purpurea grown in Taiwan. Experimental Agriculture, 44: 497507.

Çelik, S.A. (2016). Ekinezya Türlerinde Echinacea spp Bazı Sekonder Metabolitlerin Miktarlarının ve Biyolojik Aktivitelerinin Belirlenmesi, Selçuk Üniversitesi, Fen Bilimleri Enstitüsü, Doktora Tezi, Konya, 205s.

Çoksarı, G. (2012). Farklı Azotlu Gübre Dozlarında Yetiştirilen Ekinezya Türlerinde (Echinacea pallida Nutt, Echinacea purpurea (L.) Moench) Uygulanan Farklı Kurutma Yöntemlerinin Ekstrakt Kalitesi Üzerine Etkileri, Selçuk Üniversitesi Fen Bilimleri Enstitüsü Tarla Bitkileri Anabilim Dalı, Yüksek Lisans Tezi, Konya, 106s.

Dufault, R.J., Rushing, J., Hassel, R., Shepard, Mccutcheon, B.M. \& Ward B. (2003). Influence of fertilizer on growth and marker compound of field-grown
Echinacea species and feverfew. Scientia Horticulturae, 98: 61-69.

Gülpınar, A.R. (2009). Türkiye'de Kültürü Yapılan Echinacea purpurea (L.) Moench. ve Echinacea pallida (Nutt.) Nutt. Türleri Üzerinde Farmokognozik Çalışmalar. Ankara Üniversitesi, Yüksek Lisans Tezi, Ankara, 133s.

Kindscher, K. (1989). Ethnobotany of purple coneflower (Echinacea angustifolia, Asteraceae) and other Echinacea species. Economic Botany. 43(4): 498-507

Kreft, S. (2005). Cichoric acid content and biomass production of Echinacea purpurea. Plants cultivated in Slovenia. Pharmaceutical Biology, 43: 662-665.

Küçükali, K. (2012). Çukurova Koşullarında Farklı Ekim Sıklıkları ve Değişik Hasat Zamanlarının Pembe Koni Çiçeği (Echinacea Purpurea (L.) Moench)'nin Verim ve Kalitesi Üzerine Etkileri. Çukurova Üniversitesi, Fen Bilimleri Enstitüsü, Yüksek Lisans Tezi ,140s

Mat A. (2002). Echinacea türleri. 14. Bitkisel İlaç Hammaddeleri Toplantısı, Bildiriler, 29-31 Mayıs, Eskişehir, (Eds. Başer, K.H.C. ve Kırımer, N.) Web'de yayın tarihi: 2004 ISBN 975-94077-2-8. I..Ü., Eczacılık Fak., İstanbul.

Muntean, L.S., Varban, D., Muntean, S., Tamaş, M. \& Varban, R. (1998). Echinacea Species of Medicinal Use. Not. Bot. Hort. Agrobot. Cluj. 27

Omidbaigi R. (2002). Study of cultivation and adaptability of purple coneflower (Echinaceae purpurea) in the North of Tehran. Journal of Science and Technology of Agriculture and Natural Resources, Water and Soil Science, 6(2): 231-241.

Özcan, i.i. (2014). Farklı Kültürel Uygulamaların Ekinezya (Echinacea Spp) Verim ve Kalite Özeliklerine Etkisi, Adnan Menderes Üniversitesi, Fen Bilimler Ensitüsü, Aydın, 209s.

Parmenter, G., Burgmans, J., Button, L., Douglas, M., Follett, J., Gray, G. \& Smallfield, B. (1992). Production of the medicinal crops Valerian and Echinacea in New Zealand. Proceedings Agronomy Society of New Zealand, 22: 61-65.

Parmenter, G.A. \& Littlejohn, R.P. (1997). Planting density effects on root yield of purple coneflower (Echinacea purpurea (L) Moench). New Zealand Journal of Crop and Horticultural Science, 25: 169-175.

Schar, D. (1999). Echinacea: The Plant That Boosts Your Immune System. Berkeley, California: North Atlantic Books, Chapter 2.

Soldamlı, R.V. (2016). Farklı Zamanlarda Hasat Edilen Ekinezya (Echinacea purpurea (L.) Moench) Bitki Ekstraktlarının Antioksidan Aktivitelerinin Belirlenmesi, Bozok Üniversitesi, Fen Bilimleri Enstitüsü, Yüksek Lisans Tezi, 54s.

Sangwan, N.S., Farooqi, A.H.A., Shabih, F. \& Sangwan, R.S. (2001). Regulation of essential oil production in plants. Plant Growth Regulation 34: 3-21

Şahan, A. (2012). Farklı Zamanlarda Hasat Edilen Ekinezya, Echinacea pallida, Bitkisinin Biyoaktif Özellikleri ve Bitkisel Yağların Stabilitesi Üzerine Etkisi, Kayseri: Erciyes Üniversitesi Fen Bilimleri Enstitüsü, Yüksek Lisans Tezi, 118s.

Ulutaş, M. (2016). Tokat Ekolojik Koşullarında Iki Farklı Ekinezya Türünün Echinacea purpurea (L.) Moench ve E. pallida Nut. Verim ve Kimyasal İçeriklerinin Belirlenmesi. (Yüksek Lisans Tezi) Gaziosmanpaşa Üniversitesi, Fen Bilimleri Enstitüsü, 66s.

Yeşil, R. \& Kan, Y. (2013). Konya Ekolojik Şartlarında Yetiştirilen Ekinezya (E. Pallida ve E. Purpurea) türlerinin uçucu yağ verimi ve bileşenleri üzerine farklı dozlarda uygulanan organik ve inorganik gübrelerin etkileri. Selçuk Tarım ve Gıda Bilimleri Dergisi, 27(1): 14-23. 